\title{
Manifestation of Waste Silicate Type Additives and Electron Beam Irradiation on Properties of Sbr/devulcanized Waste Tire Rubber Composites for Floor Tiles Applications
}

Khaled F. El-Nemr

National Centre for Radiation Research and Technology

Magdy A. Ali

National Centre for Radiation Research and Technology

Yasser Gad ( $\nabla$ yasser2uk@yahoo.com )

National Centre for Radiation Research and Technology https://orcid.org/0000-0002-6973-0701

\section{Research Article}

Keywords: styrene-butadiene rubber, devulcanized waste tire rubber, silicate fillers, mechanical properties, floor tiles, electron beam irradiation

Posted Date: July 26th, 2021

DOl: https://doi.org/10.21203/rs.3.rs-742944/v1

License: (c) (i) This work is licensed under a Creative Commons Attribution 4.0 International License.

Read Full License 


\title{
Manifestation of waste silicate type additives and electron beam irradiation on properties of SBR/devulcanized waste tire rubber composites for floor tiles applications
}

\author{
Khaled F. El-Nemr ${ }^{\mathrm{a}}$, Magdy A. Ali ${ }^{\mathrm{a}}$, Yasser. H. Gad \\ a-Radiation Chemistry Department, National Centre for Radiation Research and Technology, P.O. Box 29 \\ Nasr City, Egyptian Atomic Energy Authority, Cairo, Egypt \\ b-Polymer Chemistry Department, National Centre for Radiation Research and Technology, P.O. Box 29 \\ Nasr City, Egyptian Atomic Energy Authority, Cairo, Egypt.
}

\begin{abstract}
Virgin styrene-butadiene rubber (SBR) was replaced by devulcanized waste tire rubber (DWR) 50/50 and used as a rubber base for preparing composites to depend on different silicate types at fixed content $40 \mathrm{phr}$ (part per hundred part of rubber). All composites were mixed on a rubber roll mill and then subjected to electron beam irradiation to induce cross-linking at a dose of $100 \mathrm{kGy}$. Different silicate fillers were used in this study like precipitated silica (PS) $40 \mathrm{phr}$, waste glass window (WG) - PS 20/20 phr, fly ash (FA)-PS 20/20 phr, and micaosilica (MS)-PS 20/20 phr. Waste silicate was treated with (3aminopropyl)trimethoxysilane (APTMS) and blended with PS. Mechanical properties were investigated for composites like tensile strength, elongation at break, tensile modulus, and calculation of cross-link density from mechanical. As well as, application for floor tiles included compression set and abrasion resistance measurements. All results indicated an enhancement in tensile strength, modulus, and cross-link density by adding silicate fillers and more enhanced in presence of radiation. For the application of floor tiles, the MS filler gave a good compression set and abrasion resistance followed by other silicate fillers (PS, FA), except WG.
\end{abstract}

Keywords: styrene-butadiene rubber, devulcanized waste tire rubber, silicate fillers, mechanical properties, floor tiles, electron beam irradiation.

Corresponding author: Yasser. H. Gad, yasser2uk@yahoo.com

\section{Introduction}

The significance of polymer reprocessing has seriously increased through the latest years. Eco-friendly and cost-effective strategies have been utilized for 
waste management. Rubber is a significant constituent in the civic solid wastes. It has to be reclaimed after discarding [1]. The blending of reclaimed rubber with virgin polymer matrix diminishes the expense of the final product and supports in lessening the environmental contamination. Numerous techniques [2] were tried to lessen this ecological burden by providing well-organized procedures for waste rubber (WR) reprocessing. The presence of worn-out tires in landfills acts as nourishing media for insects to spread diseases. Besides, tire scarps can produce poisonous fumes upon ignition which leads to environmental pollution [3]. Discarded tire rubber as a vulcanized polymer is one of the solid waste pollutants that cannot be disposed of easily with its cross-linked arrangement. Sulfur is one of the used chemicals for rubber vulcanization through composing both $\mathrm{S}-\mathrm{S}$ and $\mathrm{C}-\mathrm{S}$ bonds creating a cross-linked matrix. Upon devulcanization, the $\mathrm{S}-\mathrm{S}$ and $\mathrm{C}-\mathrm{S}$ bonds are predictable to separate; nonetheless, this does not occur perfectly. For a fruitful devulcanization step, the cross-linked structure needs to separate without chain scission. Devulcanization techniques incorporate mechano-chemical, reclaiming, grinding, devulcanization microwave, and ultrasonic processes. Among these techniques, rubber mechano-chemical devulcanization is utilized. This is achieved by converting the vulcanized or scrap waste rubber mechanically and chemically at high temperatures into a beneficial material ready to be devulcanized and processed [4].

A wide assortment of particulate fillers is utilized in the rubber industry to revise and improve the physical properties of elastomeric materials. The addition of filler frequently prompts an expansion in modulus and significant abrasion and tear resistance. Although the mechanisms of reinforcement are not completely understood, there is an overall agreement about the essential process adding to the stress-strain conduct of the filled vulcanizate [5]. Numerous kinds of fillers are utilized for the improvement of mechanical properties. Carbon black is the most extensively utilized filler in rubber industries owing to its particulate nature and higher surface area, which grants high reinforcing capacity. Nonetheless, these days, more consideration is being paid to nonblack mineral fillers such as silica, owing to the monotonous color and the high costs of carbon black. Looking for lessening the cost of composite, new materials are being considered to supplant absolutely or somewhat the customary ones as a simple economical measure or to grant some required properties. Numerous efforts have been made to utilize silica 
from the characteristic assets as substitute reinforcing filler in synthetic and natural rubbers in light of cost investments, better dimensional dependability, excessive mechanical properties, and environmental issue. Silica has various hydroxyl groups on the surface, which results in strong filler interaction and absorption of polar materials by hydrogen bonding. In the meantime intermolecular hydrogen bonding between hydroxyl groups on the surface of silica is very strong; it can form tight aggregates $[6,7]$. The best approach to keep away aggregation is to enhance the compatibility between rubber and silica to lessen the silica migration. Thus, hydrated silica confers better physical properties to polar synthetic rubbers than it doesn't to nonpolar rubbers such as styrene-butadiene rubber (SBR), natural rubber, and so on and is utilized to create colored articles that need high strength properties [8].

New methodologies were explored by researchers to replace carbon black to diminish the utilization of petroleum. This prompts the institution of inorganic fillers such as silica [9] into the rubber, which assists with creating colored products. Silica is the most widely recognized inorganic filler utilized in the rubber industry for reinforcement $[10,11]$, conversely, the isolated silanol groups and hydrogen-bonded silanol groups on the surface of silica decrease its compatibility with non-polar rubber [8]. So, silica was revised with silane coupling agents [11, 12] to make it compatible with non-polar rubbers and hybrid filler systems [13] were likewise utilized nowadays.

The reason for consolidating inorganic filler into the polymer network isn't just to accomplish exceptional properties of polymer composites but also to diminish the expense. For ecological protection and sustainable improvement, people have required an excessive effort to manufacture polymer/FA composites that come across the necessity of practical application $[14,15]$.

Blending has to turn out to be the effective technique for growing the utilization of unique materials, and of accomplishing certain necessary properties, by joining the good original properties of individual parts. Rubber blends have established increasing consideration from numerous researchers around the world [16]. Silica (silicon dioxide) is the most bountiful mineral on the Earth [17]. Silica can be utilized as filler for rubber [18], which is utilized in the manufacture of numerous products, like tires and other industrial materials. Its numerous benefits 
include: improving the mechanical durability, shrinkage, heat resistance, thermal extension, and stress of the rubber-established composite. These merits are owing to the substitution of a soft matrix by hard inorganic filler. The silica was improved with silane coupling agents, preceding its application as reinforcement filler for the NR/SBR blend. The alteration prompted the improvement of the mechanical properties and thermal degradation. Composites dependent on the silica and modified-silica filled rubber [19], have been broadly studied.

Fly ash is unavoidably created as waste after burning. About 750 million tons of fly ash is produced yearly, nonetheless, just $39 \%$ can be reused in the U.S [20]. If fly ash is discharged to the environment via air and wind, a severe contamination problem would be made with the hazard of pneumonic diseases. Recycling fly ash is an effective method to avoid such contamination. Comparable carbon black (CB) and precipitated silica, fly ash can likewise go about as reinforcing filler to enhance the mechanical properties of rubber compounds. Palmconstructed fly ash can be utilized to modify the mechanical properties of thermoplastic materials [21]. Glass waste that got from the metropolitan district can use as a brick added substance [22].

Everywhere in the world, the issue of disposing of waste tires is increasing day by day due to the growth in the number of vehicles on the road. The burning of tires and direct landfilling strategies prompts environmental degradation. Because of the non-biodegradable nature, the decomposition of wastes in the environment takes much time [23].

Upon manufacturing polymer blends or composites, gamma irradiation can be utilized to improve the compatibility between the ingredients by achieving the polymerization method. Besides, better interaction initiates with enhanced interfacial adhesion between composite components at low irradiation doses promoting improved properties without degrading the polymeric network [24].

In this study, we prepared styrene-butadiene rubber (SBR)/devulcanized waste tire as a rubber base for preparing composites depend on different silicate types and afterward exposed them to electron beam irradiation to induce crosslinking.

\section{Materials and techniques}




\subsection{Materials}

SBR.Europrene ${ }^{\circledR} 1502$, SBR virgin rubber acquired by cold polymerization, Mooney viscosity ML $1+4\left(100{ }^{\circ} \mathrm{C}\right)=52$, bound styrene, $23.5 \mathrm{wt} \%$, provided by Versalis S.p.A. company, Piazza Boldrini, San Donato Milanese (MI), Italy.

- TMTD, a reclaiming agent of the molecular formula $\mathrm{C}_{6} \mathrm{H}_{12} \mathrm{~N}_{2} \mathrm{~S}_{4}$, molecular weight $240.43 \mathrm{~g} / \mathrm{mol}$ and density $1.43 \mathrm{~g} / \mathrm{cm}^{3}$, provided by Zhedong Rubber Auxiliary Co., Ltd., China.

- Stearic acid, M.wt. $=284.49$, molecular formula: $\mathrm{CH}_{3}\left(\mathrm{CH}_{2}\right)_{16} \mathrm{COOH}$, melting point: $54{ }^{\circ} \mathrm{C}$, PROLABO, France.

- Zinc oxide ( $\mathrm{ZnO})$, a white to yellow tined powder, $98.0 \%$ purity commercialgrade, contains lead sulfate $0.25 \%$ maximum and calcium residue $0.15 \%$ maximum, El Nasr Chemical Co. Egypt.

- 1,2-dihydro-2,2,4-trimethyl quinolone (TMQ) as an antioxidant in the form of brown granular beads with the chemical formula $\left(\mathrm{C}_{12} \mathrm{H}_{15} \mathrm{~N}\right) \mathrm{n}, \mathrm{n}=2-4$, specific gravity: $1.05 \mathrm{~g} / \mathrm{cm} 3$, provided by Alfa Aesar GmbH, Germany.

- (3-Aminopropyl) trimethoxysilane (APTMS): Mw $179.20 \mathrm{~g} / \mathrm{mol}$, molecular formula C6H17NO3Si and density $0.903 \mathrm{~g} / \mathrm{cm}^{3}$, was supplied by Sigma Aldrich., Germany.

- Silicate additives are four different types of silica-containing fillers additives. Waste-Glass (WG), commercial soda-lime-silica glass, was utilized with the chemical compositions of WG particles used in this study are listed in Table I.

Silica bypass form ferromanganese byproduct named, Micaosilica (MS), that provided from Egyptian Ferroalloys Co., Egypt) has the next chemical composition presented in Table 1

Fly Ash (FA), having a density of $2.33 \mathrm{~g} / \mathrm{cm}^{3}$ and total evaporable moisture content of $1.54 \%$ was formed from the ignition of coal as a byproduct. The particle size of FA falls in the range of $63 \mu \mathrm{m}$. The chemical composition of the FA (utilized in this study) was characterized by Energy dispersed X-ray analysis (EDX) as presented in Table 1. 
Precipitated silica, SUPERSIL-140, was provided from Supersil Chemical Company, Mumbai, Maharashtra, India. SUPERSIL-140, having a bulk density of $0.235 \mathrm{~g} / \mathrm{cm}^{3}$, has a surface area of $140-170 \mathrm{~m}^{2} / \mathrm{gm}$, contains $89 \% \mathrm{SiO}_{2}, 16-18 \mu \mathrm{m}$ particle size, L.O.I at $1000 \mathrm{oC}$ is $10 \mathrm{wt}$ \%.

Table 1: Chemical composition of WG, MS and FA particles

\begin{tabular}{|c|c|c|c|c|c|}
\hline \multicolumn{2}{|c|}{ Waste Glass (WG) } & \multicolumn{2}{|c|}{ Micaosilica (MS) } & \multicolumn{2}{|c|}{ Fly Ash (FA) } \\
\hline $\begin{array}{c}\text { Chemical } \\
\text { oxides }\end{array}$ & Content \% & $\begin{array}{c}\text { Chemical } \\
\text { oxides }\end{array}$ & Content \% & $\begin{array}{c}\text { Chemical } \\
\text { oxides }\end{array}$ & Content \% \\
\hline $\mathrm{SiO}_{2}$ & 71.9 & $\mathrm{SiO}_{2}$ & 90 & $\mathrm{SiO}_{2}$ & 59.23 \\
\hline $\mathrm{Fe}_{2} \mathrm{O}_{3}$ & 0.08 & $\mathrm{Fe}_{2} \mathrm{O}_{3}$ & 4 & $\mathrm{Fe}_{2} \mathrm{O}_{3}$ & 5.03 \\
\hline $\mathrm{Al}_{2} \mathrm{O}_{3}$ & 0.66 & $\mathrm{Al}_{2} \mathrm{O}_{3}$ & 1.5 & $\mathrm{Al}_{2} \mathrm{O}_{3}$ & 32.16 \\
\hline $\mathrm{CaO}$ & 8.6 & $\mathrm{CaO}$ & 1 & $\mathrm{CaO}$ & 0.99 \\
\hline $\mathrm{MgO}$ & 4.05 & $\mathrm{MgO}$ & 1.5 & \multirow[t]{6}{*}{$\mathrm{TiO}_{2}$} & \multirow[t]{6}{*}{2.59} \\
\hline $\mathrm{K}_{2} \mathrm{O}$ & 0.037 & $\mathrm{~K}_{2} \mathrm{O}$ & 1.5 & & \\
\hline $\mathrm{Na}_{2} \mathrm{O}$ & 14.25 & $\mathrm{Na}_{2} \mathrm{O}$ & 0.5 & & \\
\hline $\mathrm{TiO}_{2}$ & 0.025 & \multirow{3}{*}{$\begin{array}{c}\text { L.O.I. at } 750 \\
{ }^{\circ} \mathrm{C}\end{array}$} & \multirow[t]{3}{*}{2} & & \\
\hline $\mathrm{SO}_{3}$ & 0.32 & & & & \\
\hline $\begin{array}{l}\text { Impurities } \\
\text { (Ni and } \mathrm{Mn} \text { ) }\end{array}$ & 0.078 & & & & \\
\hline
\end{tabular}

\subsection{Modification waste silicate additives by APTMS silane}

$100 \mathrm{~g}$ of silicates types fillers were mixed with $100 \mathrm{~mL} 5 \mathrm{wt} \%$ solution of APTMS in ethanol/water $(80 / 20 \mathrm{v} / \mathrm{v})$ in a polyethylene beaker under constant stirring by a Teflon rod, followed by removal of solvent via evaporation for $30 \mathrm{~min}$ in an oven overnight at $50{ }^{\circ} \mathrm{C}$, the dry fillers were then ground into fine powders at $64 \mu \mathrm{m}$ particle size.

\subsection{Preparation of rubber composites}

The SBR/DWR blends at 50/50 wt. \%, the method for preparation of these blends was presented in previous work [25], and this composition was taken in this 
study, according to superlative mechanical properties gained for this blend. Composites of this blend and other additives were prepared in an open mill as stated in Table 2. Subsequent to mixing, the samples were hot-pressed at $160{ }^{\circ} \mathrm{C}$ under $10 \mathrm{MPa}$ for $5 \mathrm{~min}$ into sheets of fitting thickness and size for examination.

Table 2: Formulations for prepared SBR/ DWR composites utilizing different silica additives.

\begin{tabular}{|c|c|c|}
\hline Ingredients & Blank sample(phr) & Composites (phr) \\
\hline 50/50 SBR/DWR (wt. \%) & 100 & 100 \\
\hline ZnO & 5 & 5 \\
\hline Stearic acid & 2 & 2 \\
\hline TMQ & 1 & 1 \\
\hline Precipitated silica (PS) & 0 & 40 \\
\hline FA : PS & 0 & $20: 20$ \\
\hline GW : PS & 0 & $20: 20$ \\
\hline MS : PS & 0 & $20: 20$ \\
\hline
\end{tabular}

\subsection{Electron beam irradiation of prepared blends}

Irradiation of samples was done by utilizing electron beam accelerator (Energy $3 \mathrm{MeV}$, power $90 \mathrm{~kW}$, Beam current $30 \mathrm{~mA}$, conveyer speed 16m/min $(50 \mathrm{HZ})$ and scan width variable up to $90 \mathrm{~cm}$ ) at the National Center for Radiation Research and Technology (NCRRT), Cairo, Egypt. The rubber blends were exposed to electron beam irradiation at ambient conditions for 100kGy.

Note: this dose of radiation $100 \mathrm{kGy}$ was acquired, as it is appropriate dose for good mechanical properties of SBR/DWR 50/50 wt. \% blends [25].

\subsection{Mechanical measurements}

The tensile properties of the dumbbell-shaped samples were estimated by utilizing a Universal mechanical computer-aided testing machine, V1.6 Model HDB6004B-S, made by Haida International equipment LTD Company, Daojiao town, Dongguan city, Guangdong province, China with calibrated load cell, 5000 N. The ASTM D 412-16 techniques were followed in determining the next 
mechanical properties: Elongation at break, tensile strength, modulus at $100 \%$ and $300 \%$ strain respectively. The average value of all mechanical parameters had been estimated for the prepared samples measured using at least three identical samples. A crosshead speed of $500 \mathrm{~mm} / \mathrm{min}$ was utilized and the experiments were implemented at $25{ }^{\circ} \mathrm{C}$. Shore hardness (Shore A) has been estimated for all samples utilizing Shore hardness A according to ASTM.

The compression set was done out as indicated by ASTM D 395-85 on a standard test specimen of the cylindrical shape of $16 \pm 0.1 \mathrm{~mm}$ diameter and $6 \pm$ $0.5 \mathrm{~mm}$ thicknesses. The test sample was located between the plates of the compression gadget with the spacers on each side of it, permitting enough clearance for expanding the rubber when compacted. The bolts were squeezed so the plates are drawn together consistently until they are in contact with the spacers. The assembled compression device was then placed at room temperature $20{ }^{\circ} \mathrm{C}$ for $22 \mathrm{~h}$. The test sample was lastly removed and permitted to cool for $30 \mathrm{~min}$, and the final thickness could be estimated by an electronic digital caliper with $0.01 \mathrm{~mm}$ accuracy. The compression set is defined as:

$$
C \%=\left(\frac{t_{o}-t_{1}}{t_{o}-t_{s}}\right) \times 100
$$

Where $t_{0}$ is the original thickness of the sample; $t_{1}$ is the thickness of the sample after removal from the clamp, and $t_{\mathrm{s}}$ is the thickness of the spacer bar utilized. Abrasion resistance tests were made by utilizing an abrasion tester type AP.40 (Maschinebau GmbH Rauenste in Thuringen, Germany). The loss in the mass percent was determined by ASTM D 3389-75 (1982), by equation (2):

$$
\text { Mass loss }(\mathrm{mg}) \text { per revolution }=\left(\frac{W_{i}-W_{f}}{n}\right) \times 1000
$$

Where $\mathrm{W}_{\mathrm{i}}$ is the initial mass of sample $(\mathrm{g}), \mathrm{W}_{\mathrm{f}}$ is the final mass of sample $(\mathrm{g})$, and $\mathrm{n}$ is the number of revolutions, 84 revolutions. 


\subsection{Determination of cross-link density of rubber networks determined from mechanical data}

Measurement of stress-strain response gives a simple technique for assessment of the cross-link density of polymer networks. As indicated by the classical kinetic theory of rubber elasticity was initially developed by Wall, Flory, James and Guth [26]. They ascribed the high elasticity of a cross-linked rubber to the variation of the conformational entropy of long flexible molecular chains. The theory predicts the following relation in simple extension; equation 3 :

$$
\sigma=A_{\Phi} v_{e} K T\left(\lambda^{2}-\lambda^{-1}\right)
$$

Where $\sigma$ is the true stress, the force per unit area measured in the strained state, $v_{\mathrm{e}}$ is the number of effective plastic chains per unit volume, $\mathrm{K}$ is Boltzmann's constant, $\mathrm{T}$ is the absolute temperature, and $\lambda$ is the extension ratio; $\mathrm{A}_{\Phi}$ is a prefactor depending on the considered model. The elasticity of natural and SBR rubbers in simple extension at a constant strain rate was studied [27]. They plotted the true stress as a function of $\left(\lambda^{2}-\lambda^{-1}\right)$ as recommended by the molecular theory. They acquired a series of straight lines which don't go through the origin. In contrast, rubber elasticity theory predicts that the relation between the tensile strength and the elongation ratio, $\lambda$, is illustrated in equation 4 :

$$
\sigma=\sigma_{o}(\lambda)+E\left(\lambda^{2}-\lambda^{-1}\right)
$$

Where $E$ is the modulus of elasticity and $\lambda$ is the extension ratio of the strain that happened because of the applied stress. The relation between $\left(\lambda^{2}-\lambda^{-1}\right)$ and stress $(\sigma)$ for rubber blends or composites were drawn in figures. From these figures, it has been calculated the slope of the lines represent these relations, and then tried to calculate the average molecular weight Mc between cross-links from the value $(\mathrm{G})$ as shown in equation 5 :

$$
G=3 E=A_{\Phi} \rho R T / M_{c}
$$

Where $\mathrm{G}$ is the shear modulus, $\rho$ is the density of the rubber and $\mathrm{R}$ the gas constant, the value of $\mathrm{M}_{\mathfrak{c}}$, the molecular weight between two cross-links can be determined and then the cross-link density $v$ (CD) can be determined from equation 6:

$$
\text { Crosslink density }(\mathrm{v})=1 / 2 M_{c}
$$

Thus cross-link density is contrarily proportioned with double the molecular weight between two cross-links. Consequently, cross-link density was established 
to be directly proportional to the true tensile modulus as indicated by equations 5 and 6.

\subsection{FTIR investigation.}

The chemical structure of the various types of silica untreated and treated with silane was analyzed by ATR-FTIR spectroscopy, Bruker Optik GmbH, Ettlingen, Germany, over the wavenumbers range $4000-500 \mathrm{~cm}^{-1}$.

\section{3- Results and discussion}

\subsection{Fourier Transform Infrared Spectrometry (FTIR)}

FTIR is utilized to study the chemical interaction between silane and silica particles. Figure 1a shows a typical FTIR spectrum for micaosilica $\left(\mathrm{SiO}_{2} \sim 90 \%\right)$ and its silane treatment. From the spectrum, the bands at 797 and $477 \mathrm{~cm}^{-1}$ are the characteristic bands of amorphous silica [28]. The strong broad band at approximately $1100 \mathrm{~cm}^{-1}$ corresponds to the frequency range of the siloxane group ( $\mathrm{Si}-\mathrm{O}-\mathrm{Si}$ ) vibration in silica [29]. The characteristic band located at 1620-1650 $\mathrm{cm}^{-1}$ was assigned to bending vibrations of aliphatic amine $(\mathrm{N}-\mathrm{H})$ groups. The surface of silica will usually contain an appreciable concentration of hydroxyl groups $(-\mathrm{OH})$, the broad absorption band at $3300-3730 \mathrm{~cm}^{-1}$ is due to the stretching vibration silanol groups ( $\mathrm{Si}-\mathrm{OH})$, hydroxyl groups (water or alcohol) stretching by hydrogen bonding [30]. When the MS particles are treated silane, a new two bands appeared at 2853 and $2923 \mathrm{~cm}^{-1}$ characteristic to asymmetric and symmetric stretching vibrations of $-\mathrm{CH}_{2}$ indicating grafting of APTMS on the surface of MS [31], the intensity of $\mathrm{OH}$ peak at $3300-3730 \mathrm{~cm}^{-1}$ due to hydrogen bonding, besides stretching vibrations of aliphatic amine $(\mathrm{N}-\mathrm{H})$ groups for silane was not affected, despite, the involvement of the $\mathrm{OH}$ groups during the reaction of silane with silanol group of silica, as shown in figure 2 [31]. Furthermore, for the fly ash $\left(\mathrm{SiO}_{2} \sim 59.23 \%\right)$, In raw fly ash (FA), the broad peak at $3412 \mathrm{~cm}^{-1}$ was ascribed to the stretching and deformation vibrations of $\mathrm{OH}$ and $\mathrm{H}-\mathrm{O}-\mathrm{H}$ groups from the water molecules, the presence of silica and alumina induced different linkages which have different vibration modes for identification. High intensity of $\mathrm{Si}-\mathrm{O}-\mathrm{Si}$ at $1435 \mathrm{~cm}^{-1}$ and $\mathrm{Si}-\mathrm{O}-\mathrm{Al}$ at $870 \mathrm{~cm}^{-1}$ [32] as shown in figure $1 \mathrm{~b}$. FA treated by silane shows the change in the intensity of the $\mathrm{OH}$ groups in silica, which resulted in lower reactivity of FA for silane than in the case of MS. FTIR spectra $\mathrm{GW}\left(\mathrm{SiO}_{2} \sim 71.9 \%\right)$ untreated with silane showed the same characteristic peaks of silica and after treated with silane the characteristic peak of silane is 
present with little change in the intensity of the $\mathrm{OH}$ groups in silica, which resulted in a lower quantity of hydrogen bond than in the case of MS as shown in Figure 1c.
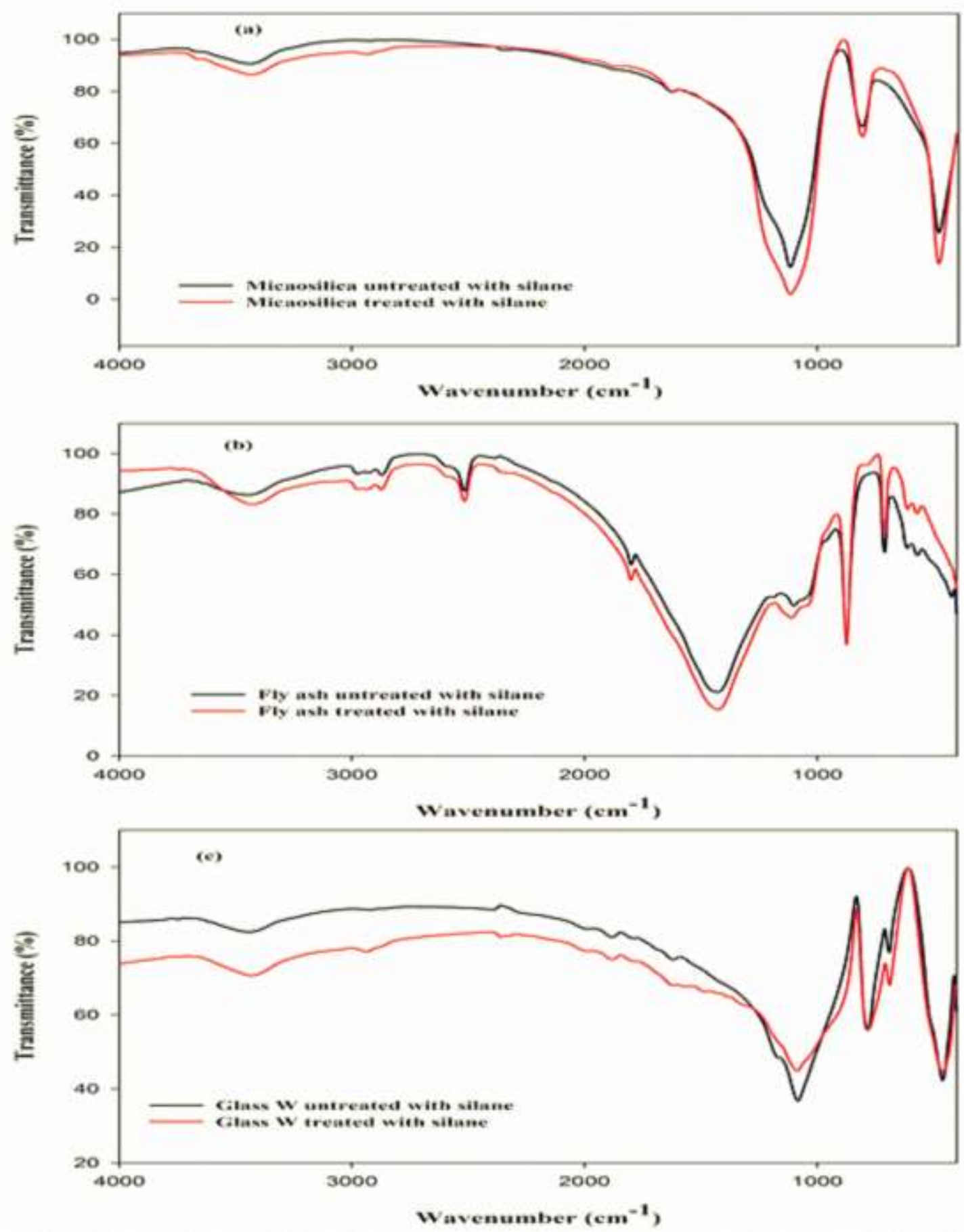

Figure 1: FTIR of (a) Micaosilica, (b) Fly ash, and (c) Glass waste untreated and treated with silane, respectively. 


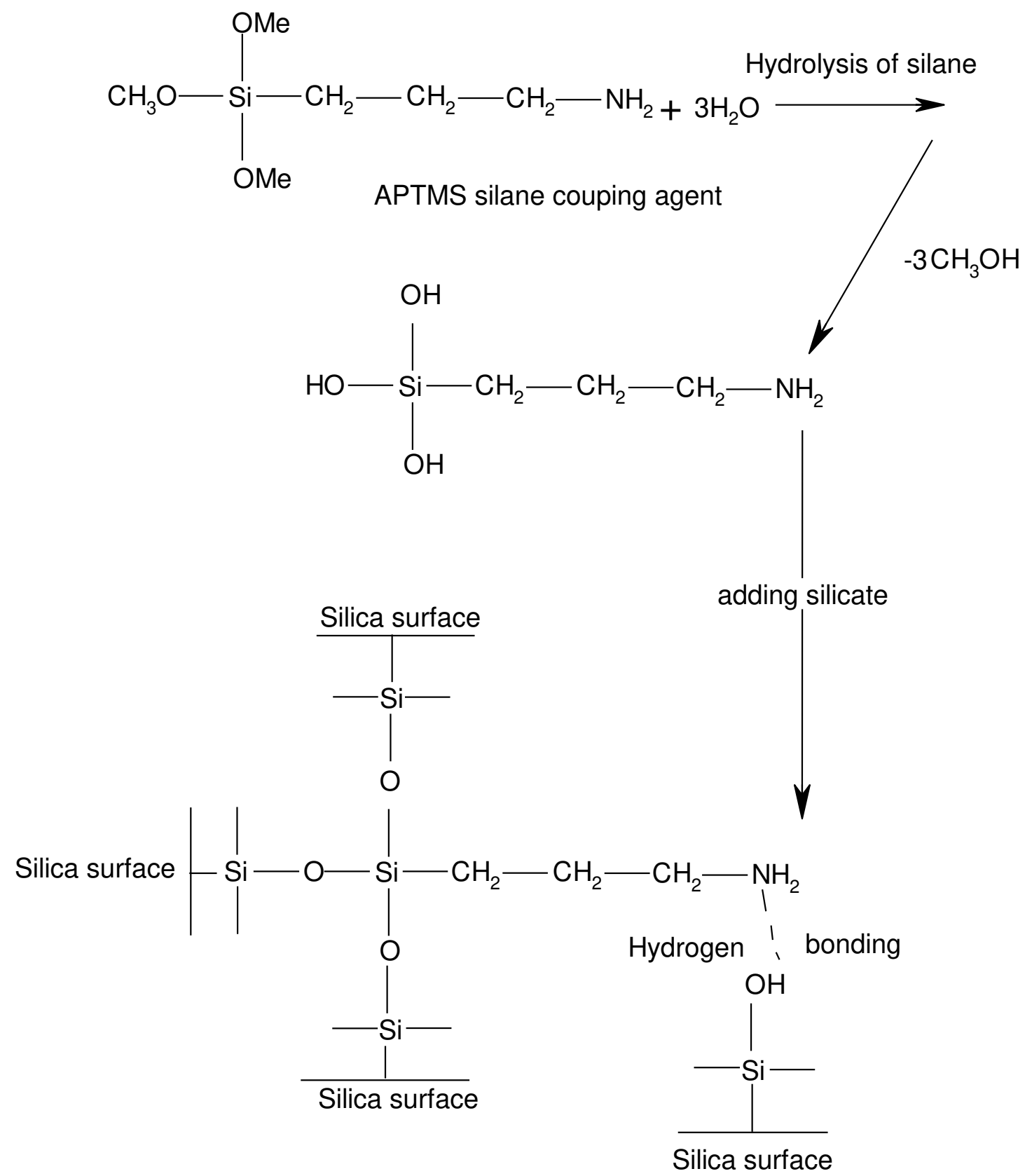

Figure 2: The scheme represents the possible reaction between the silane coupling agent and silicate surfaces. 


\subsection{Mechanical properties}

\subsubsection{Tensile strength}

Figure 3 represents the tensile strength (TS) for SBR/DWR 50/50 composites that unirradiated and irradiated at $100 \mathrm{kGy}$, also loaded with different silicate fillers with fixed concentrations namely, $40 \mathrm{phr}$. For unirradiated composites, the TS increases by addition silicate fillers; whatever it is, when compared with control samples; not contain fillers, and composites loaded by PSMS 20/20 provided the highest values for TS, followed by PS, PS-MS 20/20, and finally PS-GW 20/20. The noticeable increase in TS of composites by PS-MS, due to MS contain high content of $\mathrm{SiO}_{2}$ more than $90 \%$, and by treated it by silane, it adhered by creating chemical bonds by silanol groups on the surface of silica, in addition to forming hydrogen bonds between rubber matrix and PS. Alternatively, irradiated composites provided the highest values for TS, when compared with unirradiated ones for the same silicate filler, and irradiated SBR/DWR 50/50 composites that loaded with PS-MS 20/20 gave the highest values for TS as discussed before, as well as increasing cross-link density caused by electron beam radiation that formed free radicals and produces link macromolecules of rubber with each other form one hand, and like of macroradicals of rubber with filler on the other hand. It is observed that irradiated composites loaded with PS-GW 20/20, PS, and PS-FA 20/20 gave comparable values for TS, due to the lower content of silica in it, when compared with MS. Also the increases of TS by radiation due to physical bonds formed between rubber matrix and silicate fillers by radiation. 


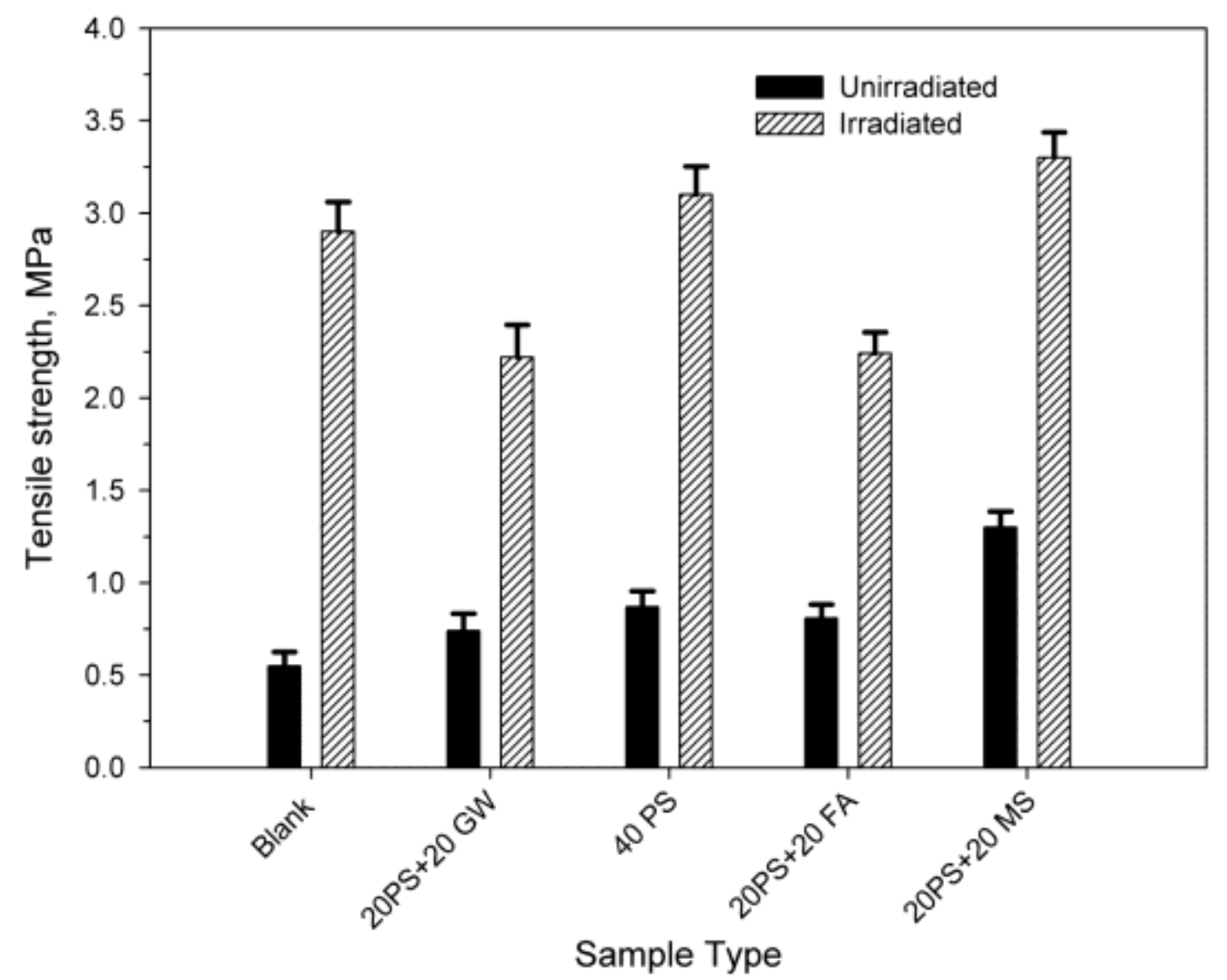

Figure 3: Tensile strength for SBR/DWR 50/50 composites loaded with $40 \mathrm{phr}$ of different silicate fillers, unirradiated and irradiated at $100 \mathrm{kGy}$.

\subsubsection{Elongation at break}

Figure 4 exhibits the $\mathrm{E}_{\mathrm{b}} \%$ for SBR/DWR 50/50 composites that unirradiated and irradiated at $100 \mathrm{kGy}$, also loaded with different silicate fillers with fixed concentration namely, $40 \mathrm{phr}$. Generally, for unirradiated composites, the $\mathrm{E}_{\mathrm{b}}$ decreases with the addition of silicate fillers, due to the filler restrict stretching. On the other hand, irradiated composites i.e blank samples, and also loaded ones, the $E_{b}$ increases by radiation for the same composites. For blank samples increases $E_{b}$ by radiation owing to liberation of carbon black in DWR which resulted in a decrease in $E_{b}$. On the other hand, the $E_{b}$ increases by radiation for all silicate fillers owing to cross-linking not enough to retard elongation due to SBR rubber contain phenyl ring that dissipates the energy of electron beam irradiation, besides, it has low $\mathrm{G}(\mathrm{X})$ (cross-link/100 eV) about 0.3 when compared with other rubbers [33]. 


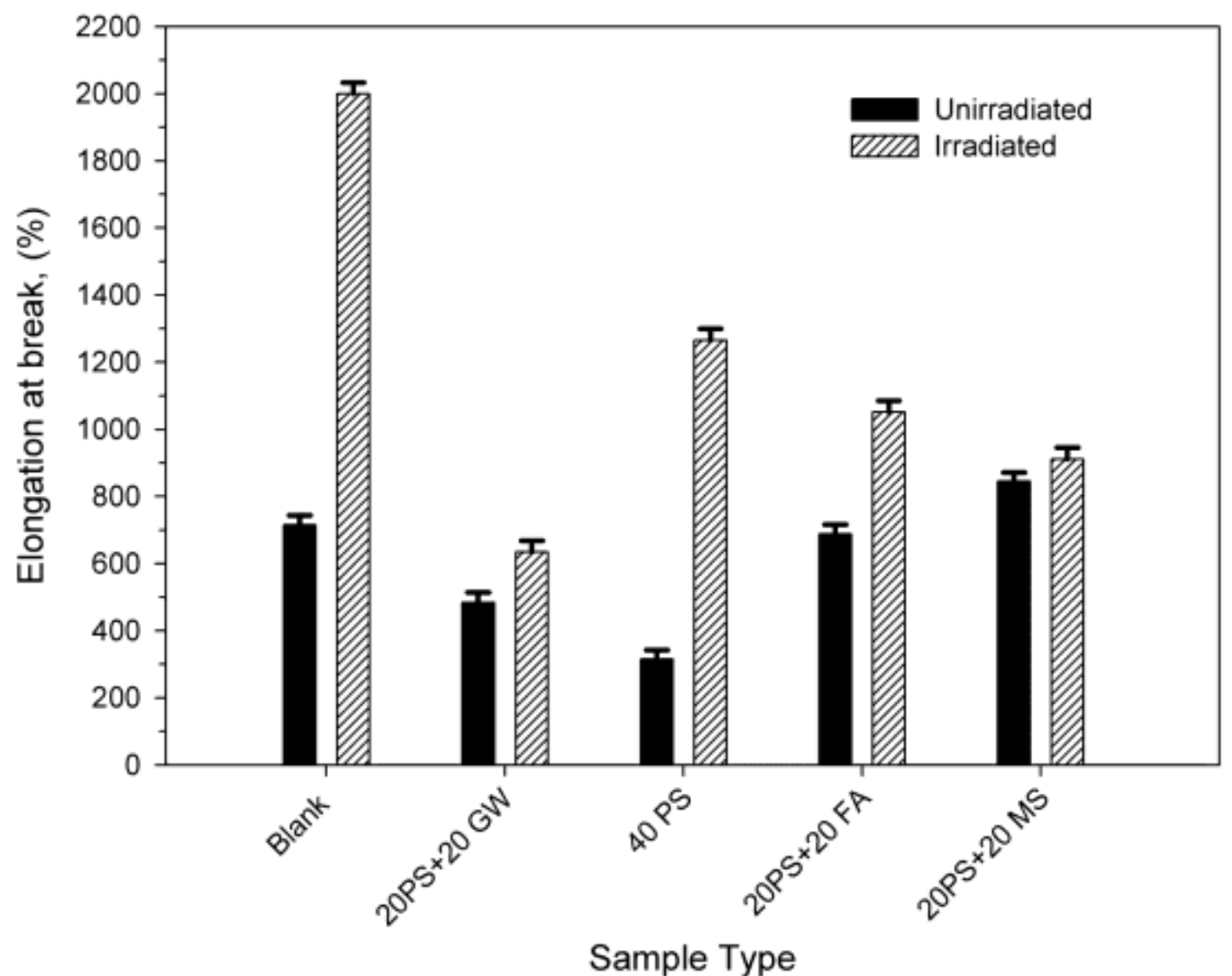

Figure 4: Elongation at break for SBR/DWR 50/50 composites loaded with $40 \mathrm{phr}$ of different silicate fillers, unirradiated and irradiated at $100 \mathrm{kGy}$.

\subsubsection{Tensile modulus at 100 and $300 \%$ elongation}

Figure $5 \mathrm{~A}$ and $\mathrm{B}$ shows $\mathrm{M}_{100}$ and $\mathrm{M}_{300}$ respectively for SBR/DWR 50/50 composites that unirradiated and irradiated at $100 \mathrm{kGy}$, likewise loaded with different silicate fillers with fixed concentration namely, $40 \mathrm{phr}$. For unirradiated composites the $\mathrm{M}_{100}$ and $\mathrm{M}_{300}$ increase with all types of silicate fillers, and PS-MS 20/20 filler gave the highest values for modulus, meanwhile PS, PS-FA 20/20 silicate fillers presented comparable values. On the other hand, PS-GW 20/20 filler provided the lowest values for modulus when compared with other silicate fillers type, owing to the non-reactivity of $\mathrm{GW}$, however, it was treated by a silane coupling agent. Irradiated composites were denoted the same behavior, but they have the highest values for modulus when compared with unirradiated ones. Furthermore, silicate filler remain has the highest values for $\mathrm{M}_{100}$ and $\mathrm{M}_{300}$, it will be recognized that modulus at certain elongation related directly proportion to cross-link density, and composites loaded by PS-MS 20/20 have the highest cross- 
link density owing to the reactivity of MS filler to interact with SBR/DWR 50/50 in the presence of electron beam irradiation.
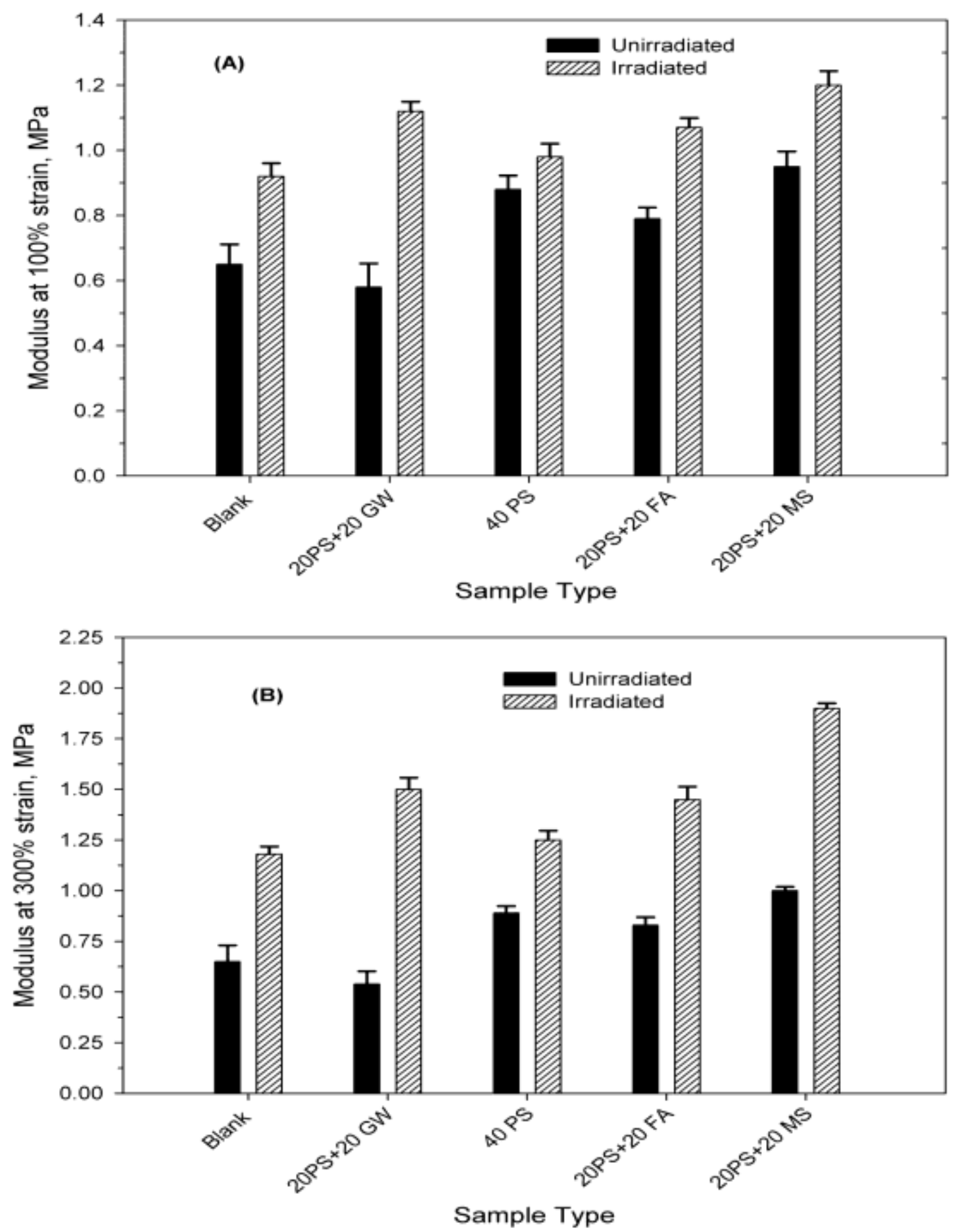

Figure 5: (A) $\mathrm{M}_{100}$ and (B) $\mathrm{M}_{300}$ for SBR/DWR 50/50 composites loaded with 40 phr of different silicate fillers, unirradiated and irradiated at $100 \mathrm{kGy}$. 


\subsubsection{Cross-link density}

Figure 6 represents the variation of the cross-link density (CD) for SBR/DWR 50/50 composites which are unirradiated and irradiated at $100 \mathrm{kGy}$, also loaded with various silicate fillers with fixed concentration namely, $40 \mathrm{phr}$. Generally, the $\mathrm{CD}$ in unirradiated composites increases with the addition of all types of silicate fillers owing to interfacial adhesion between fillers and rubber matrix. Alternatively, irradiated and loaded composites presented comparable values for $\mathrm{CD}$ for all forms of silicate fillers, but MS remains has the highest value for $\mathrm{CD}$ owing to increasing interfacial adhesion and reactivity of this silicate filler.

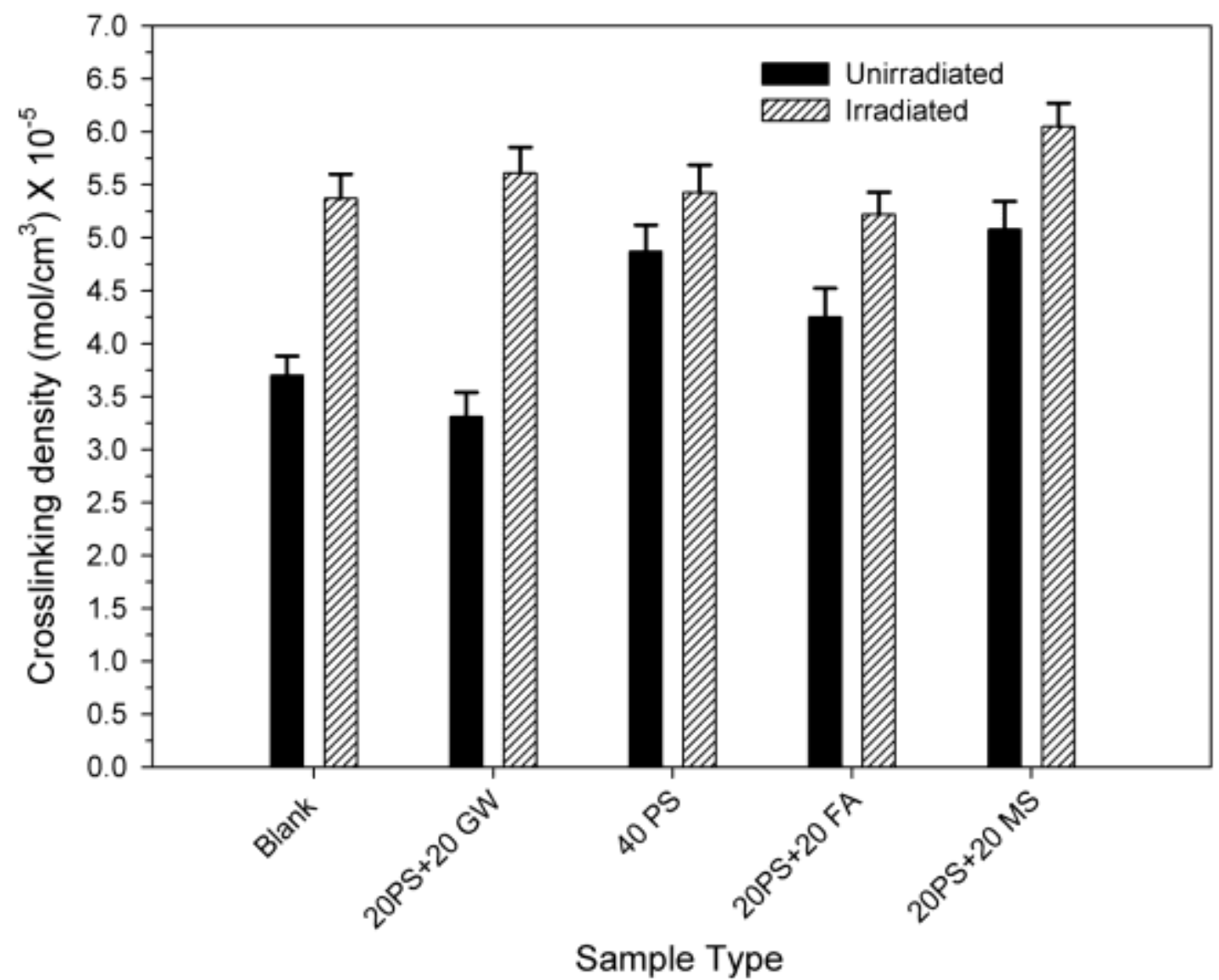

Figure 6: Cross-linking density for SBR/DWR 50/50 composites loaded with 40 $\mathrm{phr}$ of different silicate fillers unirradiated and irradiated at $100 \mathrm{kGy}$.

\subsection{Compression set}

Figure 7 elaborates the compression set for SBR/DWR 50/50 composites that unirradiated and irradiated at $100 \mathrm{kGy}$, also loaded with different silicate fillers with fixed concentration namely, $40 \mathrm{phr}$. For unirradiated composites, it can 
be observed that the blank SBR/DWR 50/50 samples have the highest compression set when compared with filled composite. At the same time, this performance was acquired in irradiated composites, but the values of compression set were decreased for the same type of silicate filler when compared with unirradiated one, owing to increased cross-link density which inversely proportional to cross-link density [ 34, 35]. Besides, it can be seen that the SBR/DWR 50/50 composites loaded by PS-MS 20/20 gave the lowest values for compression set, and this was achieved for unirradiated and irradiated ones, owing to the increased cross-link density of these composites.

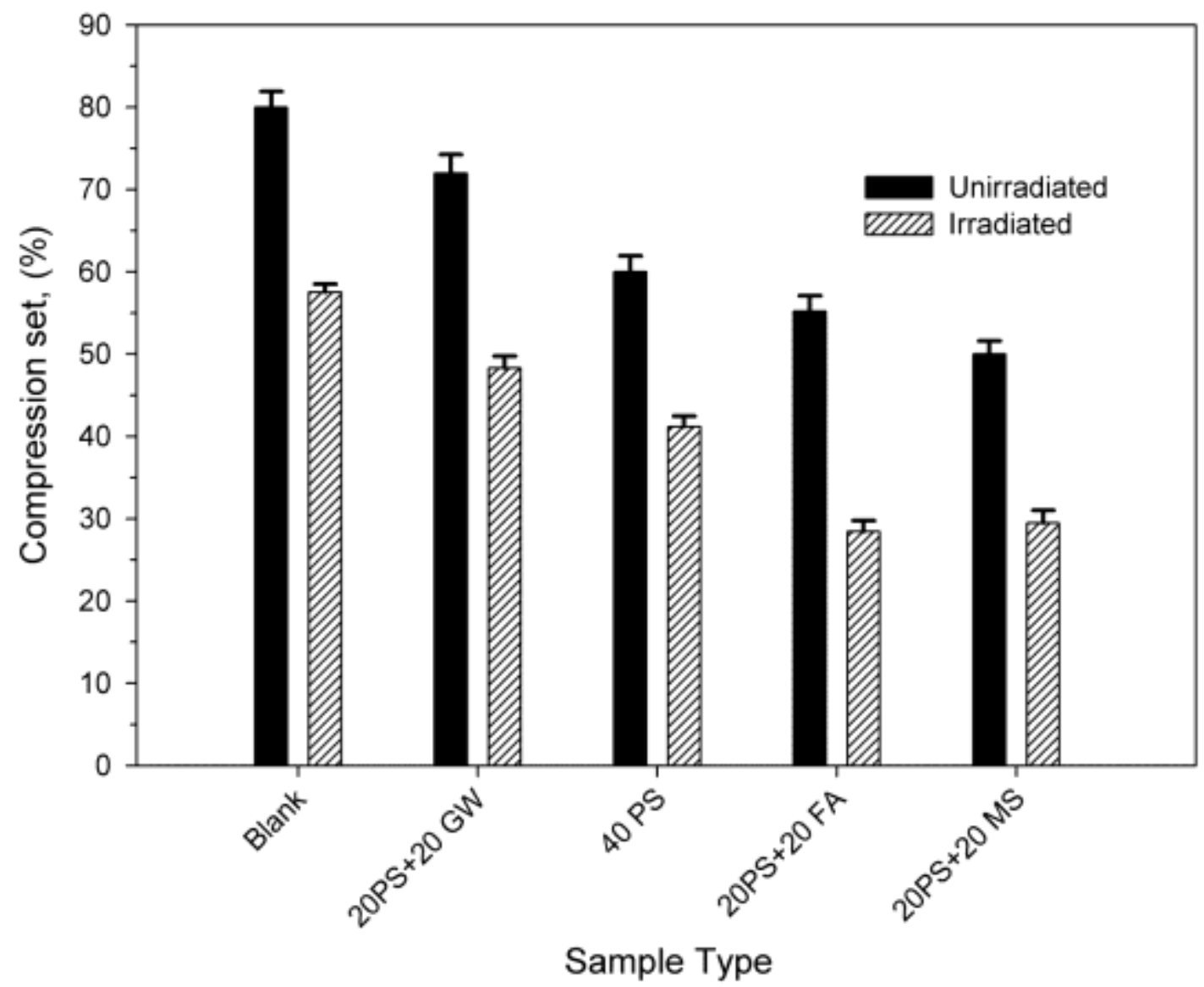

Figure 7: Compression set for SBR/DWR 50/50 composites loaded with $40 \mathrm{phr}$ of different silicate fillers, unirradiated and irradiated at $100 \mathrm{kGy}$.

\subsection{Hardness}

Figure 8 illustrates the hardness for SBR/DWR 50/50 composites that unirradiated and irradiated at $100 \mathrm{kGy}$, besides loaded with different silicate fillers with fixed concentration namely, 40 phr. For unirradiated composites, it can be 
observed that the blank SBR/DWR 50/50 samples have the lowest values for hardness for all unirradiated and irradiated composites; meanwhile, SBR/DWR 50/50 composites that loaded by PS-MS 20/20 provided the highest values for unirradiated and irradiated composites, owing to increased cross-link density. The composites loaded by PS, PS- MS 20/20, and PS-WG 20/20 provided comparable values for hardness and these for not irradiated composites and irradiated at 100 kGy.

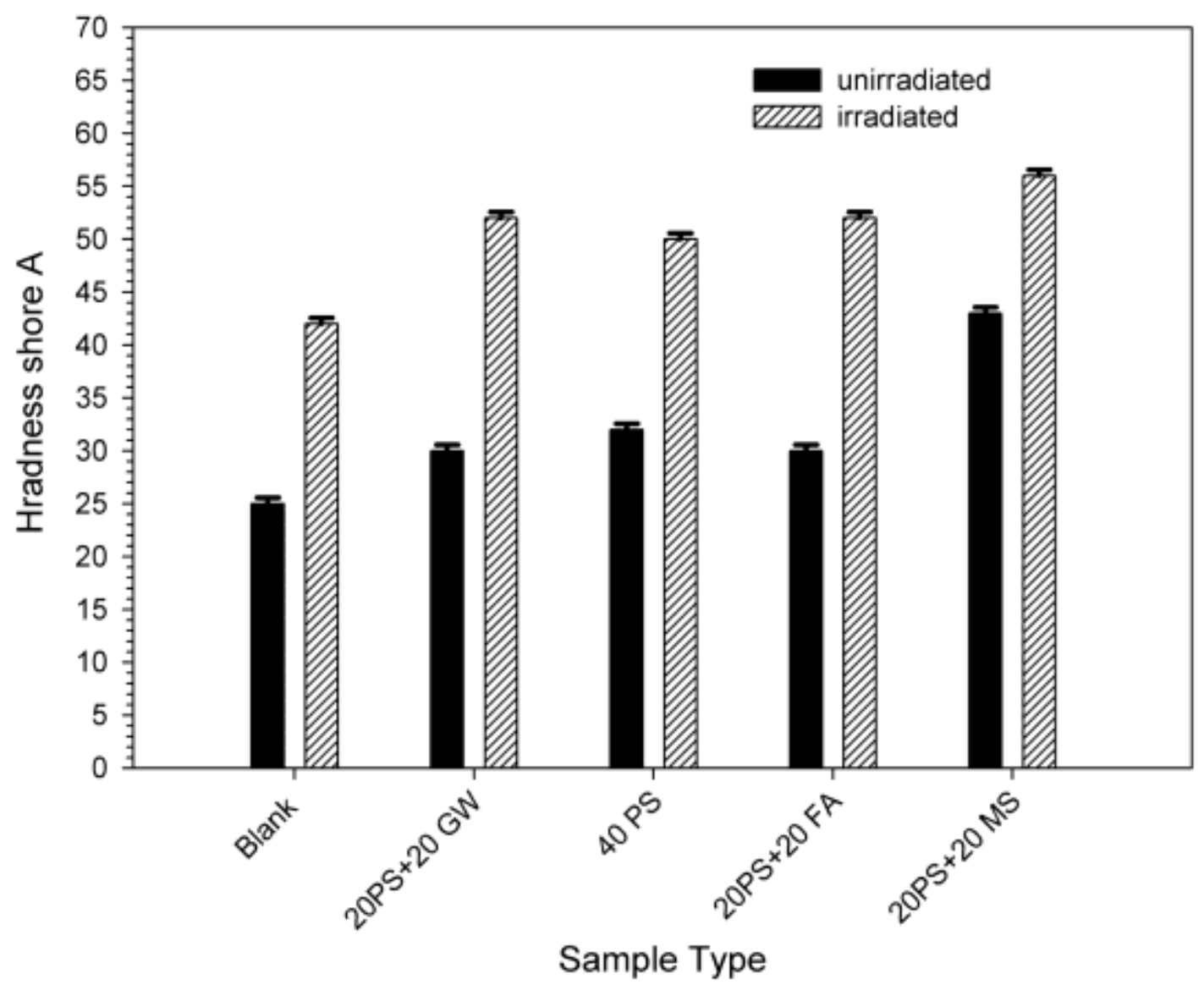

Figure 8: Hardness shore A for SBR/DWR 50/50 composites loaded with $40 \mathrm{phr}$ of different silicate fillers, unirradiated and irradiated at $100 \mathrm{kGy}$.

\subsection{Abrasion resistance}

Figure 9 demonstrates the abrasion loss for SBR/DWR 50/50 composites that unirradiated and irradiated at $100 \mathrm{kGy}$, also loaded with various silicate fillers with fixed concentration namely, $40 \mathrm{phr}$. It can be observed that, for unirradiated and irradiated SBR/DWR 50/50 composites, the abrasion resistance improved as follows; PS-MS 20/20> PS, PS-FA 20/20> PS-WG 20/20 > blank. These achieved 
results for abrasion confirmed by data discussed before in mechanical properties and cross-link density. Depending on these results of abrasion resistance, the SBR/DWR 50/50 composites loaded with silicate type PS-MS 20/20 were applicable in flooring tiles.

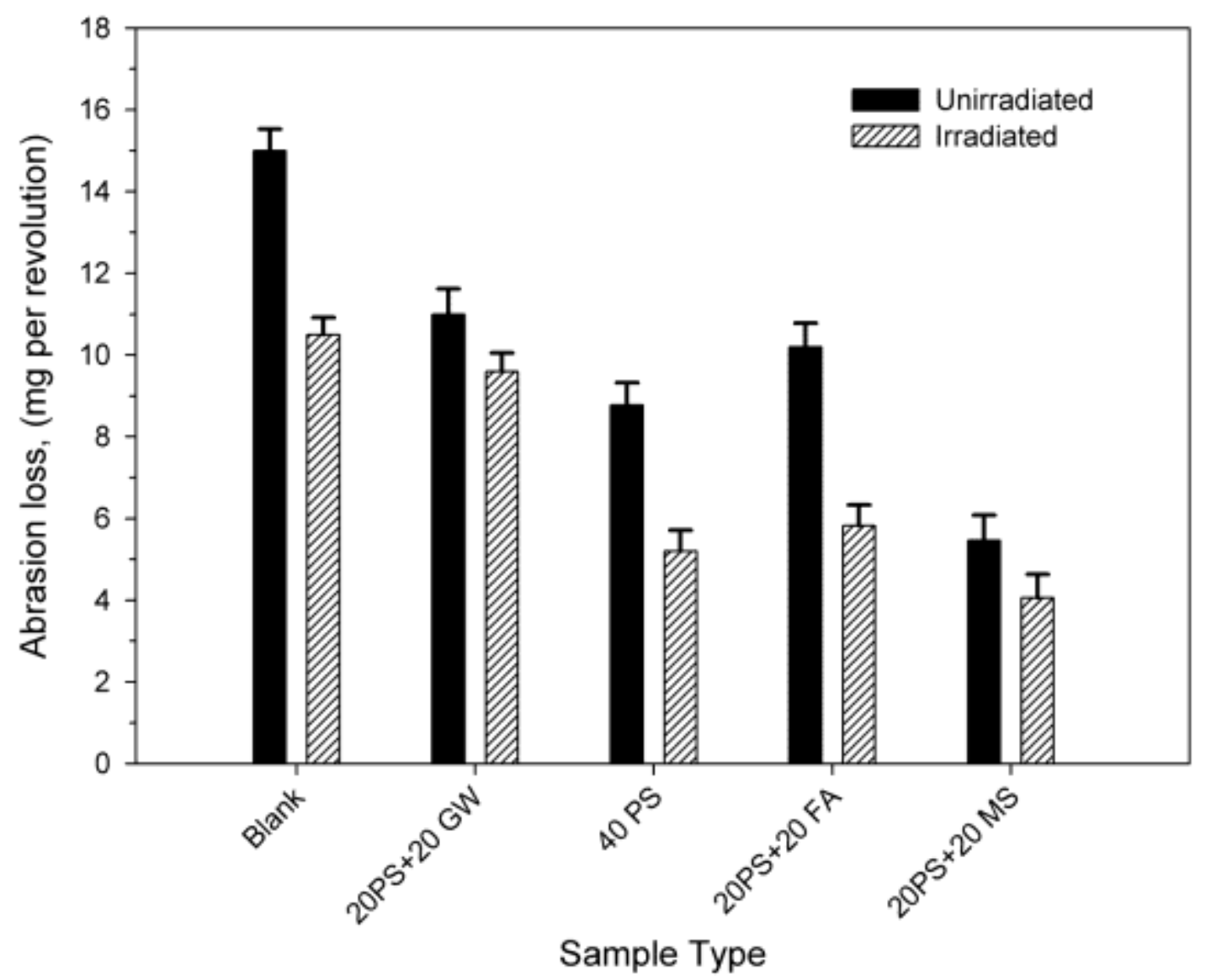

Figure 9: Abrasion loss for SBR/DWR 50/50 composites loaded with $40 \mathrm{phr}$ of different silicate fillers, unirradiated and irradiated at $100 \mathrm{kGy}$.

The properties of obtained materials have been compared with commercially available floor tiles, as presented in Table 3. It can be seen that, SBR/DWR 50/50 composites loaded with silicate type PS-MS 20/20 at irradiated at $100 \mathrm{kGy}$ were applicable in flooring tiles, the composites gave good mechanical properties when compared with others of commercially available. 
Table 3: Comparative properties of obtained applicable rubber flooring tiles with commercially available in market

\begin{tabular}{|c|c|c|c|}
\hline properties & $\begin{array}{l}\text { Waste natural } \\
\text { rubber }\end{array}$ & $\begin{array}{c}\text { Coarse-grained } \\
\text { colored } \\
\text { EPDM granules } \\
\text { bonded with } \\
\text { Polyurethane } \\
\text { elastomer. }\end{array}$ & $\begin{array}{c}\text { SBR/DWR 50/50 } \\
\text { loaded by PS- } \\
\text { MS 20/20 }\end{array}$ \\
\hline Tensile Strength, MPa & 3 & 0.3 & 3.25 \\
\hline Elongation,\% & 200 & 40 & 900 \\
\hline Hardness, Shore A & $65 \pm 5$ & $60 \pm 5$ & $55 \pm 5$ \\
\hline Thickness & $3-8 \mathrm{~mm}$ & $4 \mathrm{~mm}( \pm 0.3 \mathrm{~mm})$ & $4 \mathrm{~mm}$ \\
\hline Compression set, $\%$ & & 15 & 40 \\
\hline Supplier & $\begin{array}{l}\text { QINGDAO } \\
\text { BOTHWIN } \\
\text { CO., LTD. } \\
\text { China }\end{array}$ & $\begin{array}{c}\text { Kraiburg Relastec } \\
\text { GmbH\&Co.KG. } \\
\text { Germany }\end{array}$ & Our study \\
\hline
\end{tabular}

\section{Conclusion}

Irradiated composites loaded by PS-MS 20/20 provided the highest values for TS, followed by PS, PS-FA 20/20, and finally PS-GW 20/20, meanwhile unirradiated composites provided lower values than irradiated composites for the same type of silicate filler. In general, for unirradiated composites the $\mathrm{E}_{\mathrm{b}}$ decreases with the addition of silicate fillers, owing to the filler restrict stretching. $E_{b}$ increases by radiation for all silicate fillers due to cross-linking not sufficient to retard elongation. For unirradiated and irradiated composites the $\mathbf{M}_{100}$ and $\mathbf{M}_{300}$ increase with all types of silicate fillers, and PS-MS 20/20 filler provided the highest values for modulus, meanwhile PS, PS-MS 20/20 silicate fillers presented comparable values. Unirradiated and irradiated composites but a loaded composite provided comparable value for $\mathrm{CD}$ for all types of silicate fillers, but MS remains has the highest value for CD. SBR/DWR 50/50 composites loaded by PS- MS 20/20 provided the lowest values for the compression set. The composites loaded by PS, PS-FA 20/20, and PS-WG 20/20 presented comparable values for hardness and these for not irradiated composites and irradiated at $100 \mathrm{kGy}$. The abrasion 
resistance enhanced as follows; PS-MS 20/20> PS, PS-FA 20/20> PS-WG 20/20> blank.

\section{Ethical approval}

Not applicable

\section{Consent to participate}

Not applicable.

\section{Consent to publish}

Not applicable. All authors approved for publication.

\section{Author's contributions}

Khaled F. El-Nemr was responsible for the conception and design, testing, data acquisition, writing - review, and editing. Magdy A. Ali was responsible for analysis and data interpretation, writing - review, and editing manuscript. All authors read, revise, and approved the final manuscript. Yasser H.Gad was responsible for analysis and data interpretation, writing - review, and editing manuscript. All authors read, revise, and approved the final manuscript.

\section{Funding}

Not applicable.

\section{Availability of data and materials}

The authors declare that all data supporting the findings and materials of this study are available within the paper

\section{Conflict of interest}

The authors declare that they have no competing interests and non-financial competing interests.

\section{ORCHID}

Khaled F. El-Nemr: https://orcid.org/0000-0003-1505-6229

Magdy A. Ali: https://orcid.org/0000-0002-7983-8433

Yasser H. Gad: https://orcid.org/0000-0002-6973-0701

\section{Declarations}

The authors declare no competing interests.

\section{References}

[1] Lucia Asaro, Michel Gratton, Saïd Seghar, Nourredine Aït Hocine, (2018) "Recycling of rubber wastes by devulcanization", Resources, Conservation and Recycling 133, 250-262 
[2] Yu, B., J. Jung, K. Park, and J. B. Goodenough. (2017), “A new approach for recycling waste rubber products in Li-S batteries", Energy \& Environ. Sci. 10, 86-90. https://doi.org/10.1039/C6EE02770A

[3] Aoudia, K., S. Azem, N. A. Hocine, M. Gratton, V. Pettarin, and S. Seghar. (2017), "Recycling of waste tire rubber: Microwave devulcanization and incorporation in a thermoset resin", Waste Manage. 60:471-481.

[4] Movahed, S. O., A. Ansarifar, G. Zohuri, N. Ghaneie, and Y. Kermany. (2016), "Devulcanization of ethylenepropylene- diene waste rubber by microwaves and chemical agents", $J$. Elastomers \& Plastics 48(2) 122-144. https://doi.org/10.1177/0095244314557975

[5] Guhanathan S and Saroja DM. (2005), "Physicochemical characterization of the filler-matrix interface in elastomer-encapsulated fly ash/polyester particulate composites", J Appl Polym Sci; 97(1), 171-184. https://doi.org/10.1002/app.21744

[6] Feng L, Wang Y, Wang N, and Ma Y. (2009), "Preparation of poly (ethylene glycol)-grafted silica nanoparticles using a facile esterification condensation method", Polym Bull; 63: 313-327.

[7] Wanvimon Arayapranee1 and Garry L. Rempel, (2013) "Effects of Polarity on the Filler-Rubber Interaction and Properties of Silica Filled Grafted Natural Rubber Composites", Journal of Polymers, 2013, 1-9 https://doi.org/10.1155/2013/279529

[8] Baglari S, Kole M, and Dey TK. (2011), "Effective thermal conductivity and coefficient of linear thermal expansion of high-density polyethylene-fly ash composites", Indian J Phys; 85: 559-573.

[9] Ryu C., Kim S.J., Il Kim D., Kaang S., Seo G., (2016), “The Effect of Surface Area of Silicas on Their Reinforcing Performance to Styrene-butadiene Rubber Compounds", Elastomers Compos 51, 128-137. doi:10.7473/EC.2016.51.2.128.

[10] Chen L., Jia Z., Tang Y., Wu L., Luo Y., Jia D., (2017), "Novel functional silica nanoparticles for rubber vulcanization and reinforcement", Compos. Sci. Technol. 144, 11-17. doi:10.1016/j.compscitech.2016.11.005.

[11] Zhang C., Tang Z., Guo B., Zhang L., (2018), "Significantly improved rubber silica interface via subtly controlling surface chemistry of silica", Compos. Sci. Technol. 156, 70-77. doi:10.1016/J.compscitech.2017.12.020.

[12] Sattayanurak S., Noordermeer J.W.M., Sahakaro K., Kaewsakul W., Dierkes W.K., Blume A., (2019), "Silica-Reinforced Natural Rubber: Synergistic 
Effects by Addition of Small Amounts of Secondary Fillers to SilicaReinforced Natural Rubber Tire Tread Compounds", Adv. Mater. Sci. Eng. 2019, 1-8. doi:10.1155/2019/5891051.

[13] Lee J.-Y., Park N., Lim S., Ahn B., Kim W., Moon H., Paik H., Kim W., (2017), "Influence of the silanes on the cross-link density and cross-link structure of silica-filled solution styrene butadiene rubber compounds", Compos. Interfaces. 24, 711-727. doi:10.1080/09276440.2017.1267524.

[14] Verma P., Kumar A., Chauhan S.S., Verma M., Malik R.S., Choudhary V., (2018), "Industrially viable technique for the preparation of HDPE/fly ash composites at high loading: thermal, mechanical, and rheological interpretations", J. Appl. Polym. Sci. 135, 45995.

[15] Bora P.J., Porwal M., Vinoy K.J., Kishore, Ramamurthy P.C., Madras G., (2018), "Industrial waste fly ash cenosphere composites based broad band microwave absorber", Compos. Part B Eng. 134, 151-163.

[16] Ashok N., Balachandran M., Lawrence F., (2018), “Organo-modified layered silicate nanocomposites of EPDM-chlorobutyl rubber blends for enhanced performance in c radiation and hydrocarbon environment", J Compos Mater 52, 1-13. https://doi.org/10.1177/ 0021998318763504.

[17] Mebert A.M., Baglole C.J., Desimone M.F., Maysinger D., (2017) "Nano engineered silica: properties, applications and toxicity", Food Chem Toxicol 109(Pt 1),753-770. https://doi.org/10.1016/j.fct.2017.05. 054.

[18] Spratte T., Plagge J., Wunde M., Klüppel M. (2017), "Investigation of strain induced crystallization of carbon black and silica filled natural rubber composites based on mechanical and temperature measurements", Polymer, 115,12-20. https://doi.org/10.1016/j.polymer. 2017.03.019.

[19] Chen L., Jia Z., Tang Y., Wu L., Luo Y., Jia D. (2017), "Novel functional silica nanoparticles for rubber vulcanization and reinforcement", Composites Science and Technology, 144,11-17. https://doi.org/10.1016/j. compscitech.2016.11.005.

[20] Ranjbar, N., Kuenzel, C., (2017). Cenospheres: A review. Fuel 207, 1-12. https://doi.org/10.1016/J.FUEL.2017.06.059.

[21] Bahruddin, Ahmad A., Prayitno A., Satoto R., (2012), "Morphology and Mechanical Properties of Palm Based Fly Ash Reinforced Dynamically Vulcanized Natural Rubber/Polypropylene Blends", Procedia Chem. 4, 146153. https://doi.org/10.1016/j.proche.2012.06.021. 
[22] Phonphuak N., Kanyakam S., Chindaprasirt P., (2016) "Utilization of waste glass to enhance physical-mechanical properties of fired clay brick", Journal of Cleaner Production., 112, 3057-3062, doi:10.1016/j.jclepro.2015.10.084.

[23] Girskas G., Nagrockiene D., (2017) "Crushed rubber waste impact of concrete basic properties, Construction and building materials", 140, 36-42, doi:10.1016/j.conbuildmat.2017.02.107.

[24] Martinez-Lopez M. G. Martinez-Barrera C., Barrera-Diaz F. Urena-Nunez, and dos Reis J. M. L., (2016), "Waste Tetra Pak particles from beverage containers as reinforcements in polymer mortar: Effect of gamma irradiation as an interfacial coupling factor", Constr. Build. Mater. 121, 1-8.

[25] Khaled F. El-Nemr, Heba A. Raslan, Magdy A.M. Ali and Medhat M. Hasan. (2020), "Innovative $\gamma$ rays irradiated styrene butadiene rubber/reclaimed waste tire rubber blends: a comparative study using mechano-chemical and microwave devulcanizing methods", Journal of Polymer Engineering, 40 (3), 267-277.

[26] Treloar L. R. G., "The Physics of Rubber Elasticity", Oxford University Press; 3rd edition (2005).

[27] Yong-Hua Zang, René Muller, and Daniel Froelich, (1986), "New Representation of the True Stress for Uniaxial Extension of Cross-linked Rubbers", Journal of Rheology, 30 (6), 1165.

[28] Leng P. B., Hazizan MD Akil and Ong Hui Lin, (2007), "Thermal Properties of Microsilica and Nanosilica Filled Polypropylene Composite with Epoxy as Dispersing Aid", Journal of Reinforced Plastics and Composites, 26(8), 761770 .

[29] Haccuria, M., (1953), "Spectre infra-rouge de la silice amorphe, de la tridymite, de la cristobalite, du quartz et de la silice fondue", Bulletin des Sociétés Chimiques Belges, 62(7-8),428-435.

[30] Gao, X., He, J., Deng, L., and Cao, H., (2009), "Synthesis and characterization of functionalized rhodamine B-doped silica nanoparticles", Optical Mater., 31(11), 1715-1719.

[31] Hsu_Tung Lu, (2013), "Synthesis and Characterization of Amino_Functionalized Silica Nanoparticles"|, Colloid Journal, 75(3), 311-318. [32] Amir Naveed, Noor-ul-Amin, Fazli Saeed, M. Khraisheh, Mustafa Al Bakri, Saeed Gul, (2019) "Synthesis and characterization of fly ash based 
geopolymeric membrane for produced water treatment", Desalination and Water Treatment, 161, 126-131.

[33] Magdy A. Ali, Khaled F. El-Nemr and Medhat M. Hassan. (2011), "Waste newsprint fibers for reinforcement of radiation-cured styrene butadiene rubber based composites - Part I: Mechanical and physical properties". J. of reinforced plastics and composites, 30(8), 721-737. https://doi.org/10.1177/0731684411407949

[34] Shibulal Gopisathi, Changsin Park, Yang Il Huh, Jinseok Jeon, Chang Hyun Yun, Joohye Won, Kwang-Un Jeong, Changwoon Nah, (2019), "Enhancing the reversion resistance, cross-linking, and thermos-mechanical properties of accelerated sulfur cured chlorobutyl rubber using 4, 4-bis (maleimido) diphenyl methane. Rubber Chemistry and Technology, 92 (1), 110-128.

[35] Saeed Ostad Movahed, Ali Ansarifar, Farnaz Mirzaie, (2015), "Effect of Various Efficient Vulcanization Cure Systems on the Compression Set of a Nitrile Rubber Filled with Different Fillers". J. Appl. Polym. Sci. 132(8), 41512. https://doi.org/10.1002/app.41512 